\title{
Promoting intercultural competence in study abroad students
}

\author{
Christian Tarchi ${ }^{1}$ (D) Alessio Surian ${ }^{2}$
}

Received: 28 December 2020 / Revised: 30 March 2021 / Accepted: 31 March 2021 / Published online: 16 April 2021

(C) The Author(s) 2021

\begin{abstract}
Universities have been promoting study abroad programmes for a long time to improve intercultural competence. However, the mere exposure to cultural differences while studying abroad does not ensure intercultural competence, unless study abroad students' reflective processes are explicitly targeted. The article presents the results of a short intervention grounded in the problem-based approach aimed at improving intercultural competence in study abroad students. Students were assigned to three conditions: a videolog condition (in which they have to narrate a critical incident occurred to them), a reflection-induced video-logs (in which they were prompted to reflect on the video-logs produced), and an active control condition. The reflection-induced video-log intervention improved students' perceived proficiency in Italian and perceived opportunities for cultural reflection, but it did not contribute to improve students' applicable and conceptual knowledge of intercultural competence.
\end{abstract}

Keywords Intercultural competence · Acculturation - Study abroad · Intercultural education · Critical incidents

\section{Introduction}

Promoting effective and appropriate behaviour and communication in intercultural situations (i.e., intercultural competence, Deardorff, 2011) is a key objective in a world characterized by increased mobility and social interaction within multicultural environments (Olson \& Kroeger, 2001). Universities have been promoting internalization for a long time: The last 20 years have

Christian Tarchi

christian.tarchi@unifi.it

1 Department of Education, Languages, Intercultures, Literatures and Psychology, University of Florence, via San Salvi, 12 -, 50125 Florence, Italy

2 FISPPA Department of Philosophy, Sociology, Educational Sciences, and Applied Psychology, University of Padua, Padua, Italy 
seen a raise in the popularity of study abroad programmes. Most of the study abroad programmes are designed to improve academic skills (e.g., language skills), professional development (e.g., communication), personal development (e.g., open-mindedness), and intercultural competence (e.g., diminished ethnocentrism) (Anderson et al., 2006). However, a mere exposure to a different culture does not automatically increase intercultural understanding (Engberg et al., 2016; Lantz-Deaton, 2017).

Study abroad students' gains in intercultural competence may depend on individual variables, such as their initial competence (Anderson et al., 2006) or acculturation levels (Tarchi et al., 2019), as well as contextual variables, such as reflective opportunities offered by host and local institutions, besides pre-departure and pre-return orientation meetings (Engberg et al., 2016; Vande Berg et al., 2012). Reflective opportunities may depend as well on teaching staff qualifications to manage an international classroom; thus, more research is needed on ways to improve intercultural competence through targeted interventions embedded in study abroad programmes. This study investigated the efficacy of an intervention aimed at improving intercultural competence by fostering study abroad students' reflection on their own significant experiences by tracking and analysing critical incidents. A critical incident is any observable human activity that is sufficiently described for the observer to understand the purpose of the act, to make inferences and predictions about the person performing the act and reflect on the consequences involved (Flanagan, 1954). When used in intercultural settings, critical incidents describe situations in which there is a misunderstanding, a problem or a conflict that arises from cultural differences (Fitzgerald, 2001; Wight, 1995).

\section{Intercultural competence}

A consensus on the definition of intercultural competence has not been achieved yet (Deardorff, 2011). Over 30 intercultural competence models and hundreds of related constructs are mentioned in recent reviews (Holt \& Seki, 2012; Spitzberg \& Changnon, 2009). Studies in this field tend to focus on intercultural competence as a set of personal characteristics resulting in individual differences (Sandberg, 2000). Leung et al. (2014) cluster three main domains in relation to intercultural competence: (a) intercultural traits, (b) intercultural capabilities, and (c) intercultural attitudes and worldviews. The latter is particularly relevant to the present study. It analyses individual differences in terms of cosmopolitan outlook (Bird et al., 2010; Javidan \& Teagarden, 2011), category inclusiveness (Bird et al., 2010), and ethnocentric-ethnorelative cultural worldviews (Bennett, 1986, 1993; Hammer, 2011). The intervention presented hereafter looks at the last category which is also termed "intercultural sensitivity." In this study, we relate it to specific dimensions of intercultural competence as defined by Deardorff (2006) drawing from two sets of empirical data: the results of a questionnaire completed by institutional administrators of internalization strategies and those from a Delphi technique used to develop consensus by international scholars who are experts in intercultural communication. This process led to a four-component model: attitudes, knowledge and comprehension, internal outcomes, and external outcomes. Attitudes include respect, openness, curiosity, and discovery. Knowledge and comprehension include processes such as cultural self-awareness, deep cultural knowledge, sociolinguistic awareness, listening, observing, analysing, interpreting, and relating. Internal outcomes include adaptability, flexibility, ethnorelative view, and empathy. External outcomes include effective and appropriate communication and behaviour in intercultural situations. Thus, intercultural competence and intercultural sensitivity are two separate constructs with some degree of 
interdependence concerning the affective and attitude aspects related to understanding and appreciating cultural differences. As Chen and Starosta (1996) explain "in order to develop a positive emotion towards understanding and appreciating cultural differences and eventually promote the ability of intercultural competence, interculturally sensitive persons must possess the following elements: self-esteem, self-monitoring, open-mindedness, empathy, interaction involvement, and nonjudgment." This involves "the ability of an individual to distinguish between the different behaviours, perceptions, and feelings of a culturally different counterpart and the ability to appreciate and respect them as well" (Chen \& Starosta, 1997). Concerning the interdependence between intercultural competence and intercultural sensitivity, Hammer et al. (2003) suggest that intercultural sensitivity refers to "the ability to discriminate and experience relevant cultural differences," while intercultural competence refers to "the ability to think and act in interculturally appropriate ways" (p. 422). Through increasing levels of intercultural sensitivity, increasing degrees of proficiency in intercultural competence become possible. This is particularly relevant in considering how to scaffold study abroad experiences in order to trigger and support the development of intercultural competence on the basis of students' cultural encounters and misunderstanding. In order for these events to turn into insightful experiences, it is necessary to support students' reflection on them (Engberg et al., 2016; Lantz-Deaton, 2017). One way to scaffold such reflection is the video-log technique (Wong \& Webster, 2012). Our previous studies provide evidence that the intercultural sensitivity construct offers a proper framework to elicit reflection on video-logs in relation to cultural diversity issues (Author, 2019). Therefore, in the present study, we aim at investigating to what extent an instructional intervention based on video-log reflection is generating positive outcomes in terms of developing intercultural competence.

\section{Variables associated to intercultural competence}

Past research has emphasized the contribution of several variables on the development in intercultural competence, including language competence, prior experiences, immersion, and acculturation. Certainly, if a sojourner understands and speaks the host language, he or she will be facilitated in communicating effectively (Mamman, 1995). While this claim may be trivial, more interesting is the fact that the ability to speak any language other than students' $\alpha$ native language, and not necessarily the hosts' one, seem to be associated with higher intercultural competence (Mamman, 1995). Students' perception of competence too is a relevant variable. Students who felt competence in using a non-native language had a higher intercultural competence than students who did not feel competent in foreign languages (Cui, 2016). Shannon and Begley (2008) found that multilingual students are characterized by higher intercultural competence because they rely more on language as a method to interact with the host culture. Bennett et al. (2003) speculated that advanced levels of language proficiency lead to better intercultural competence (as assessed through intercultural sensitivity). However, the relationship between language proficiency and intercultural competence seems more complex than hypothesized by previous authors. According to Jackson (2011), intercultural competence development while studying abroad does not necessarily parallel language competence. For instance, if students are taught the local language in academic contexts with very limited interactions with people from the host culture, the development of intercultural competence was slower.

Study abroad students with prior experiences with different cultures have higher gains in intercultural competence than their peers who are studying abroad for their first time 
(Mamman, 1995). In a study conducted by Behrnd and Porzelt (2012), having being abroad increased study abroad students' intercultural competence and made intercultural training more beneficial for them.

Quantity and quality of cultural immersion too are important factors for development. The more people interact with people of different backgrounds the higher their intercultural competence is (Cui, 2016). The quantity and quality of interaction with members of the host country was found associated with gains in study abroad students' self-efficacy perception (Cubillos \& Ilvento, 2012). How often students intentionally push themselves outside of their comfort zones and immerse themselves in the culture of the host country, explore new habits and behaviours, and interact with residents of the host country outside of the classroom was found to be a powerful mediator of global learning outcomes in study programme outcomes (Engberg et al., 2016).

Acculturation was found associated with intercultural competence in prior research. Acculturation refers to the psychological changes occurring when individuals learn to cross boundaries (Akkerman \& Bakker, 2011; Berry, 1997). This process is the result of the interaction between participants' orientations towards the heritage and the host culture (Berry, 1974, 2005). Individuals may have a high orientation towards both cultures, resulting in an integration acculturative strategy. Or they may have a high orientation towards their heritage culture (but not towards the host culture), resulting in a separation acculturative strategy. The opposite pattern leads to an assimilation acculturative strategy. Finally, individuals may have a low orientation toward both, the host and heritage culture, resulting in a marginalization acculturative strategy. For instance, Tarchi et al., (2019) have found that US study abroad (all students were from the USA and were enrolled in English-speaking courses abroad) students had a higher orientation towards their heritage culture than Erasmus Mundus study abroad students (students came from several countries in the world, and were enrolled in courses taught in English), and were also characterized by a lower performance in intercultural competence. The authors suggested the existence of an association between these two results.

\section{Promoting intercultural competence}

The mere exposure to cultural differences while studying abroad does not ensure intercultural competence (Engberg et al., 2016; Lantz-Deaton, 2017), unless study abroad students' reflective processes are explicitly targeted (Deardorff, 2009; Paige \& Vande Berg, 2012; Vande Berg et al., 2012). While several authors have developed comprehensive programmes, training or workshops targeting intercultural competence to be implemented as self-standing packages (see for instance IDRAcademy, https:// www.idrinstitute.org/), there is a scarcity of school-based interventions. An exception is represented by Busse and Krause' intervention studies (2015, 2016) to test the efficacy of a problem-based intercultural learning unit for secondary school students. The authors designed an intercultural learning unit promoting empathy and perspective taking in order to improve intercultural competence. The unit was grounded on a problem-based learning approach: students worked with authentic problems in the form of cultural incidents, that is, scenarios displaying misunderstandings or conflicts that arise as a result of cultural differences (Flanagan, 1954). According to their results (Busse \& Krause, 2016), the problem-based approach was successful: students 
in the experimental groups made better learning progress, both regarding their understanding of the term intercultural competence (i.e., conceptual knowledge) and their ability to apply the knowledge gained through the learning unit to critical incidents conceptual knowledge (i.e., applicable knowledge), than students in the control groups.

Notwithstanding the relevant contribution of this study to our understanding on how intercultural competence can be improved within educational settings, a few aspects may limit its generalizability. As authors themselves noted, the quasi-experimental research design reduces the internal validity of the study. Moreover, the authors used fictious critical incidents (although based on authentic incidents experienced by peers), rather than having students reflect on their own critical incident.

Moreover, drawing from Kolb's model of experiential learning (Kolb, 1984; Kolb et al., 2001), learning can be considered as a process of extracting personal meaning from experience through conscious reflection (Larzén-Östermark, 2011). Individuals learn and develop by participating in social activities with others, a consideration that seems particularly relevant for intercultural experiences. Following this line of thinking, study abroad students' perception of the quantity and quality of intercultural relations may play a key role in their intercultural competence development.

\section{The use of narratives in intercultural research}

Narratives are considered a powerful means for individuals to extract personal meaning from experience, especially when events do not unfold as expected. But individuals may not be fully aware of the influence of their own cultural background on their thinking and may be needed to be guided in this process. Recently, the advent of digital communication has influenced our storytelling practices. Communicating with image, sound, and text could ease interactions that are otherwise limited by linguistic differences and spatio-temporal boundaries. Past research has suggested video-logs as a promising tool to elicit students' own critical incidents while studying abroad (Tarchi et al., 2019). Video-logs are personal narratives in which the medium is the video (Wong \& Butler, 2012). Thus, we suggest that video-logs can be used as a means to elicit personal reflection on critical incidents through storytelling. Videologs can be used also to expose individuals to the stories told by others who are sharing the same experiences, but who might interpret them in different ways.

The present study aims at assessing the efficacy of an intervention to improve intercultural competence in study abroad students. To extend current research, we designed a short intervention grounded in the problem-based approach, with students' reflecting on their own critical incidents, adopting a pre- and post-test control group design. Past studies indicate that storytelling is a powerful strategy for meaning-making of experiences that unfold in an expected way, but the effectiveness of this strategy may be optimal if individuals are exposed to different narratives of similar experiences and if they are guided through their reflection. To determine whether the effects depend on students producing their own cultural incidents or on prompting students' reflection on their critical incident, we created two different experimental conditions: video-log condition (VL) or reflection-induced video-logs (RVL). These two experimental conditions were compared to an active control condition. The efficacy of the intervention was tested 
on gains in conceptual and applicable knowledge of intercultural competence, acculturation orientation, and immersion in the culture.

This research design allows to investigate whether intercultural sensitivity and intercultural competence are causally linked: does an intervention on the former produce an effect on the latter one? Intercultural sensitivity is a powerful construct for reflecting about experiences relating to cultural diversity, the same experiences that oftentimes are expected to contribute to the development of intercultural competence as an outcome - for example of study abroad experiences.

We included initial scores in (conceptual and applicable) knowledge of intercultural competence and acculturation orientation, as well as language proficiency and prior experiences of study abroad as control variables. While most study abroad programmes intend to improve intercultural competence directly, past studies have suggested that background variables may be fundamental for long-term changes. Acculturation orientation scores may limit study abroad students' ability to reflect on their own cultural experiences (Tarchi et al., 2019). Moreover, students' perceived competence in intercultural settings have been found to associated to intercultural competence (Bennett et al., 2003; Cubillos \& Ilvento, 2012; Cui, 2016; Jackson, 2011; Mamman, 1995; Shannon \& Begley, 2008); thus, it is important to verify to what extent they can be improved during a study abroad programme.

We expected for the RVL intervention to significantly improve students' conceptual and applicable knowledge intercultural competence more than the VL intervention or the control condition would (Hp1). We expected for the RVL intervention to improve students' perceived immersion in the culture (Hp2). No effect on acculturation orientation was expected, as this variable describes an initial orientation towards cultural values of our own and host culture, that a short-term experience such as a study abroad semester is not likely to change (Hp3).

\section{Method}

\section{Participants}

Participants in the present study were 71 undergraduate students from several universities in the USA (61 females and 10 males, mean age $=20.1 \pm 0.49$ ). Participants were all enrolled in study abroad programmes in Italy. Each programme lasted for a school semester, from January to April 2019. Participants were enrolled in the following study abroad courses, all taught live in English: Intercultural communication (three sections), Human development in culture (1 section), and Cross-cultural psychology (1 section). All classes were taught by the same instructor. We obtained participants' informed consent to participate in the study. The study followed all the indications of the Declaration of Helsinki (World Medical Association, 2013) and was in line with the indications of the University of Florence (IT). Ethics approval was not required at the time the research was conducted by the University of Florence (IT).

\section{Research design}

Research hypotheses were tested through a cluster-randomized research design with pre-test and post-test comparison. The research design included three steps. In the first step, pre-test measures were administered to students. In the second step, classes were randomly assigned to a condition: video-log intervention (VL, 24 students), reflection-induced video-log 
intervention (RVL, 23 students), and active control (AC, 24 students). In the third step, posttest measures were administered to students.

\section{Materials and measures}

\section{Pre-test measures}

The following measures were administered.

\section{Proficiency in languages}

The students were asked to rate their proficiency in Italian on a scale from 1 ("I have never studied or spoken Italian) to 7 ("excellent"). Moreover, students were asked whether they were bi- or multilingual: "How many languages do you speak fluently, beside English?"

\section{Prior experiences}

The students were asked whether they had previously traveled outside the USA before (Yes or No), and whether they had done a study abroad experience before the current one (Yes or No).

\section{Acculturation orientation}

Students' orientation towards host and heritage culture was assessed through the Acculturation Index (Ward \& Rana-Deuba, 1999). This self-report questionnaire includes 20 cognitive and behavioural items (e.g., clothing, pace of life, food, friendship, and the like). For each item, students are asked to rate on a 1-7 Likert scale ( $1=$ "not at all"; $7=$ "extremely") to what extent their experiences or behaviours are similar to those of people from the host culture, and to rate to what extent their experiences or behaviours are similar to those of people from the heritage culture. Two scales are calculated, a host identification score (summing up all ratings provided for similarity to people from the host culture) and a conational identification score (summing up all ratings provided for similarity to people from the heritage culture). Scores in each scale could range from 20 to 140 . The reliability score of both scales was acceptable (host scale, $\alpha=.88$; conational scale, $\alpha=.91$ ).

\section{Conceptual knowledge of intercultural competence}

This measure was drawn on Busse and Krause's study (2016). Students were asked to define what intercultural competence is: "What do you understand by intercultural competence? Please explain which aspects [e.g., abilities] are involved in that." Students' answers were coded adopting Deardorff's framework (2006). One trained researcher coded all answers with the following coding system (see Table 1). The second author of the present study acted as second rater and coded $30 \%$ of the material. Inter-rater agreement was acceptable $(k=.89)$. One point for each competence identified was assigned and a total score calculated. Scores could range between 0 and 17 . 
Table 1 Coding system for conceptual knowledge of intercultural competence

\begin{tabular}{|c|c|c|c|c|c|}
\hline Categories & Attitudes & $\begin{array}{l}\text { Knowledge and } \\
\text { comprehension }\end{array}$ & Skills & Desired external outcome & $\begin{array}{l}\text { Desired internal } \\
\text { outcome }\end{array}$ \\
\hline Competences & $\begin{array}{l}\text { Respect } \\
\text { Openness } \\
\text { Curiosity }\end{array}$ & $\begin{array}{l}\text { Cultural } \\
\text { self-awareness } \\
\text { Deep cultural } \\
\text { knowledge } \\
\text { Sociolinguistic } \\
\text { awareness }\end{array}$ & $\begin{array}{l}\text { Listen } \\
\text { Observe } \\
\text { Evaluate } \\
\text { Analyse } \\
\text { Relate }\end{array}$ & $\begin{array}{l}\text { Effective and appropriate } \\
\text { communication } \\
\text { Effective and appropriate } \\
\text { behaviour }\end{array}$ & $\begin{array}{l}\text { Adaptability } \\
\text { Flexibility } \\
\text { Ethnorelative } \\
\quad \text { view } \\
\text { Empathy }\end{array}$ \\
\hline
\end{tabular}

\section{Applicable knowledge of intercultural competence}

This measure was drawn on Busse and Krause's study (2016). Students were given two critical incidents (derived by narratives of study abroad of the previous years, see supplementary material for full text) and were asked to analyse the problem, analyse the situation from an affective perspective, identify appropriate strategies, and draw a conclusion. One trained researcher coded all answers with the following coding system (see Table 2). The second author of the present study acted as second rater and coded $30 \%$ of the material. Inter-rater agreement was acceptable $(k=.81)$. Each answer was coded on a $0-3$ scale and a total score was calculated. Scores could range between 0 and 12 .

\section{Post-test measures}

The following measures were administered.

Table 2 Coding system for applicable knowledge of intercultural competence

\begin{tabular}{|c|c|c|c|}
\hline Component & Item & Score & Definition \\
\hline \multirow{4}{*}{$\begin{array}{l}\text { Analysis of the } \\
\text { problem }\end{array}$} & \multirow[t]{4}{*}{ What happened here? } & 0 & No answer \\
\hline & & 1 & Personal reasons \\
\hline & & 2 & Taking into account a cultural reason \\
\hline & & 3 & Finding a possible cultural explanation \\
\hline \multirow{4}{*}{$\begin{array}{l}\text { Affective analysis } \\
\text { of the situation }\end{array}$} & \multirow{4}{*}{$\begin{array}{l}\text { What kind of feelings does this situation } \\
\text { probably trigger in the people involved }\end{array}$} & 0 & No answer \\
\hline & & 1 & $\begin{array}{l}\text { Understanding of the emotion but no } \\
\text { empathy }\end{array}$ \\
\hline & & 2 & $\begin{array}{l}\text { Empathizing with the emotions } \\
\text { displayed }\end{array}$ \\
\hline & & 3 & $\begin{array}{l}\text { Recognizing underlying meaning of the } \\
\text { event that triggered the emotions }\end{array}$ \\
\hline \multirow{4}{*}{$\begin{array}{l}\text { Appropriate } \\
\text { strategies }\end{array}$} & \multirow[t]{4}{*}{ How would you react in their place? } & 0 & No answer \\
\hline & & 1 & Breaking off strategies \\
\hline & & 2 & $\begin{array}{l}\text { Appropriate strategies to deal with the } \\
\text { problem }\end{array}$ \\
\hline & & 3 & Culturally appropriate strategies \\
\hline \multirow[t]{4}{*}{ Conclusions } & \multirow[t]{4}{*}{ What can we learn from this situation? } & 0 & No answer \\
\hline & & 1 & Ethnocentric conclusion \\
\hline & & 2 & $\begin{array}{l}\text { Recognizing the influence of the } \\
\text { cultural background }\end{array}$ \\
\hline & & 3 & $\begin{array}{l}\text { Recognizing the importance of } \\
\text { intercultural competence }\end{array}$ \\
\hline
\end{tabular}




\section{Proficiency in languages}

Students were asked to rate again their proficiency in Italian with the same scale as in the pretest assessment.

\section{Study abroad experience}

Students were asked to rate their immersion quantity ("My immersion in (or experience with) Italian culture has been:") on a scale from 1 to 4 (1 = "not much"; 4 = "more than I had expected"); immersion quality ("My immersion in (or experience with) Italian culture has been:") on a scale from 1 to 4 ( 1 = "disappointing"; 4 = "life-changing"); and opportunities for cultural interaction ("Opportunities to listen to and/or to speak Italian during this semester have been:" on a scale from 1 to 4 ( 1 = "not much"; 4 = "optimum");

\section{Acculturation orientation}

The same questionnaire as in the pre-test assessment was used (host scale, $\alpha=.87$; conational scale, $\alpha=.92$ ).

\section{Conceptual knowledge of intercultural competence}

The same measure as in the pre-test assessment was used. Inter-rater agreement was acceptable $(k=.93)$.

\section{Applicable knowledge of intercultural competence}

The same measure as in the pre-test assessment was used. Different cultural incidents were used (see supplementary material). Inter-rater agreement was acceptable $(k=.91)$.

\section{Procedure}

After the pre-test stage, but before the experimentation, each student received a class about intercultural competence as part as their syllabus (90 min). The topic of intercultural competence was discussed through the construct of intercultural sensitivity. The term intercultural sensitivity is sometimes used for intercultural competence (Deardorff, 2015), but it specifically refers to individuals' ability to discriminate and experience relevant cultural differences (Bennett, 1986; Hammer, 2015). The main theoretical model for this construct is the Developmental Model of Intercultural Sensitivity (DMIS, Bennett, 1986), which describes the developmental progression from ethnocentrism (i.e., experiencing one's own culture as central to reality) to ethnorelativism (i.e., experiencing cultures in relation to the specific context). The model includes six stages, three ethnocentric (denial, defense and minimization) and three ethnorelative (acceptance, adaptation, and integration). In denial, one's own culture is experienced as the only real one. In defense, one's own/adopted culture is experienced as the only good one. In minimization, elements of one's own cultural worldview are experienced as universal. In acceptance, other cultures are experienced as equally complex but different constructions of reality. In adaptation, 
one attains the ability to shift between different cultural worldviews. In integration, one's experience of self is expanded to include the movement in and out of different cultural worldviews. After this lesson, students were assigned to the three conditions. The activities in each condition were delivered by the first authors of the present study in the following lesson.

\section{Video-log intervention group}

Students were asked to produce a video-log with the following instructions: "We ask you to produce a video log about a critical incident you had while studying abroad. A video log is a video-recorded narrative in which you need to talk about an experience that you had while studying abroad that puzzled you, and very likely the puzzlement derives from a cultural difference. You need to video-record yourself (for example, through your phone), and talk for about 2-5 min." Overall, the intervention lasted 30 min (explaining instructions, showing an example, creating the video $\log$ ).

\section{Reflection-induced video-log intervention group}

Students were asked to produce a video log with the same instructions as in VL. Following students were asked to transcribe their video log, and each student was assigned five anonymous transcriptions to reflect on. Students were asked to read the transcription, assign it to a DMIS stage and explain why. Then, in class, students' reflections were presented and those video-logs that had received contrasting ratings were discussed in group. Finally, the instructor guided students in a reflection on how the way narratives were narrated was related to the cultural worldview represented. Overall, the intervention lasted $90 \mathrm{~min}$, divided in two classes: part 1 lasted $30 \mathrm{~min}$ (explaining instructions, showing an example, creating the video $\log$ ), part 2 lasted $60 \mathrm{~min}$ (plotting scores assigned on the whiteboard and classroom discussion).

\section{Active control group (control)}

The control group watched a shorter version of a movie on cross-cultural differences and cultural clashes ("Crash," directed by Paul Haggis and released in 2005). After watching the movie, they were asked to fill in a reflection sheet and had a classroom discussion. Overall, the intervention lasted 90 consecutive minutes: $60 \mathrm{~min}$ (watching the move) and $30 \mathrm{~min}$ (filling the worksheet and classroom discussion).

\section{Results}

Descriptive results and correlations among variables are reported in Tables 3 and 4. Participants reported a medium-low initial perceived competence in Italian. Eighty-two percent of the sample did not speak any other language besides English, 15\% reported to speak one foreign language, $3 \%$ reported to speak two or more foreign languages. Eighty-nine percent of the sample had traveled outside USA before the study abroad period, whereas $11 \%$ of the sample had never traveled outside USA before. Ninety-two percent had never had a prior study 
Table 3 Descriptive results

\begin{tabular}{|c|c|c|c|c|c|c|c|c|}
\hline & \multicolumn{2}{|c|}{ Total Sample } & \multicolumn{2}{|l|}{ RVL } & \multicolumn{2}{|l|}{ VL } & \multicolumn{2}{|l|}{ Control } \\
\hline & M & SD & M & SD & M & SD & M & SD \\
\hline \multicolumn{9}{|l|}{ Pre-test measures } \\
\hline Proficiency in Italian & 1.94 & 1.03 & 2.14 & 1.36 & 1.78 & .95 & 1.92 & .76 \\
\hline Languages spoken & .21 & .48 & .10 & .30 & .13 & .34 & .24 & .44 \\
\hline Experience traveling & .89 & .32 & .86 & .35 & .83 & .38 & .96 & .20 \\
\hline Experience study abroad & .08 & .28 & .05 & .21 & .13 & .34 & .08 & .28 \\
\hline Orientation to origin culture & 112.21 & 11.63 & 118.18 & 8.25 & 111.92 & 10.60 & 107.24 & 13.00 \\
\hline Orientation to host culture & 73.10 & 14.05 & 74.05 & 15.95 & 75.79 & 11.78 & 69.68 & 14.14 \\
\hline Conceptual knowledge & 12.54 & 2.03 & 12.46 & 2.28 & 12.75 & 2.09 & 12.42 & 1.84 \\
\hline Applicable knowledge & 3.60 & 1.64 & 4.04 & 2.25 & 3.13 & 1.22 & 3.60 & 1.35 \\
\hline \multicolumn{9}{|l|}{ Post-test measures } \\
\hline Proficiency in Italian & 2.87 & 1.09 & 3.41 & 1.30 & 2.74 & .96 & 2.52 & .82 \\
\hline Immersion quantity & 3.07 & .49 & 3.09 & .53 & 3.22 & .52 & 2.92 & .40 \\
\hline Immersion quality & 3.00 & .54 & 2.95 & .38 & 3.09 & .60 & 2.96 & .61 \\
\hline Opportunities & 2.60 & .75 & 2.95 & .72 & 2.57 & .73 & 2.32 & .69 \\
\hline Orientation to origin culture & 107.35 & 14.96 & 108.81 & 12.66 & 105.64 & 15.85 & 107.68 & 16.51 \\
\hline Orientation to host culture & 77.66 & 15.27 & 80.29 & 14.47 & 80.32 & 14.69 & 72.50 & 15.91 \\
\hline Conceptual knowledge & 14.23 & 2.53 & 14.18 & 2.22 & 14.05 & 3.00 & 14.45 & 2.36 \\
\hline Applicable knowledge & 4.40 & 2.22 & 4.19 & 2.16 & 4.30 & 2.43 & 4.74 & 2.02 \\
\hline
\end{tabular}

abroad experience before, whereas $8 \%$ had been already enrolled in a study abroad programme before.

Variables were correlated across time: post-test scores in perceived proficiency in Italian, orientation towards origin and host culture, and applicable and conceptual knowledge of intercultural competence were correlated with the respective initial scores. Applicable and conceptual knowledge of intercultural competence were interrelated at both time points. Initial perceived proficiency in Italian was positively correlated with perceived immersion quality, and it was negatively correlated with post-test applicable knowledge of intercultural competence. Perceived immersion quantity and quality were interrelated. Perceived opportunities

Table 4 Correlations among variables

\begin{tabular}{llllllllllllllll}
\hline Variable & 1 & 2 & 3 & 4 & 5 & 6 & 7 & 8 & 9 & 10 & 11 & 12 & 13 \\
\hline 1 & Proficiency_Italian1 & 1 & -.19 & .10 & -.16 & .04 & $.58^{* *}$ & .20 & $.29^{*}$ & .19 & -.07 & .14 & $-.27^{*}$ & -.10 \\
2 & Orientation_origin1 & 1 & .05 & -.12 & .03 & .12 & -.06 & -.002 & .04 & $.40^{* *}$ & .13 & .18 & -.06 \\
3 & Orientation_host1 & & 1 & .014 & -.04 & .12 & .11 & .21 & .10 & -.11 & $.45^{* *}$ & .02 & -.15 \\
4 & Applicable_K1 & & & 1 & $.34^{* *}$ & -.18 & -.06 & -.11 & -.03 & -.18 & -.13 & $.31^{*}$ & .15 \\
5 & Conceptual_K1 & & & & 1 & -.05 & .002 & -.03 & .20 & .04 & .04 & .17 & $.35^{* *}$ \\
6 & Proficiency_Italian2 & & & & & 1 & .13 & .20 & .22 & .002 & .14 & -.11 & -.05 \\
7 & Immersion quantity & & & & & & 1 & $.33^{* *}$ & .20 & .09 & .11 & -.05 & -.03 \\
8 & Immersion quality & & & & & & & 1 & .00 & -.03 & .16 & -.16 & .01 \\
9 & Opportunities & & & & & & & & 1 & -.08 & $.35^{* *}$ & -.04 & -.09 \\
10 & Orientation_origin2 & & & & & & & & & 1 & $.28^{*}$ & .02 & .05 \\
11 & Orientation_host2 & & & & & & & & & & & 1 & -.09 \\
12 & Applicable_K2 & & & & & & & & & & & & & $.33^{*}$ \\
13 & Conceptual_K2 & & & & & & & & & & & & & 1 \\
\hline
\end{tabular}

${ }^{* *} p<.01,{ }^{*} p<.05 . K=$ knowledge. $1=$ pre-test, $2=$ post-test 
were correlated with post-test orientation towards host culture. Post-test orientation towards origin and host culture were interrelated.

All variables were normally distributed, except for perceived proficiency in Italian the beginning of the semester and number of languages spoken. The first variable was normalized through a monotonic transformation, whereas the second variable was analysed through nonparametric statistical analyses. Prior traveling and study abroad experiences were dichotomous variables.

\section{Change over time}

Change over time was assessed through a series of repeated-measures ANOVAs.

Participants' scores in orientation towards origin culture significantly decreased over time $\left[F(1,61)=9.19, p<.01, \eta^{2}=.13\right]$, whereas scores in orientation towards the host culture increased overtime $\left[F(1,61)=6.35, p<.05, \eta^{2}=.09\right]$. Participants' perception of proficiency in Italian significantly increased over time $\left[F(1,61)=72.73, p<.001, \eta^{2}=.54\right]$. Participants significantly improved performances in applicable knowledge $\left[F(1,61)=18.27, p<.001, \eta^{2}\right.$ $=.25]$ and conceptual knowledge $\left[F(1,55)=9.18, p<.01, \eta^{2}=.14\right]$ about intercultural competence.

\section{Efficacy of intervention}

Initially, we run a series of statistical analyses to verify equivalence of groups in pre-test measures. No statistically significant among groups emerged for perceived proficiency in Italian $[F(2,67)=0.56, p=.58]$, orientation towards the host culture $[F(2,67)=1.24, p=$ .30], applicable knowledge in intercultural competence $[F(2,67)=0.19, p=.83]$, conceptual knowledge in intercultural competence $[F(2,67)=1.82, p=.17]$, numbers of language spoken $\left[\chi^{2}=0.70, p=.71\right]$, prior experience in traveling abroad $\left[\chi^{2}=2.14, p=.34\right]$, or prior experience of study abroad $\left[\chi^{2}=0.95, p=.62\right]$. Surprisingly, a significant difference emerged for orientation towards origin culture $[F(2,68)=5.92, p=.004]$, with the RVL group being characterized by a higher orientation than the control group $[p=.003]$. Thus, this variable was included as a covariate in all statistical analyses, along with initial scores of the dependent variable.

According to the ANCOVAs, group explained a significant portion of variance in post-test scores in perceived proficiency in Italian $\left[F(2,68)=3.16, p<.05, \eta^{2}=.09\right]$ and opportunities $\left[F(2,68)=4.15, p<.02, \eta^{2}=.11\right]$ (see Table 5$)$. Group was not significantly associated to post-test scores in perceived immersion quantity or quality. Post-test perceived proficiency in

Table 5 Results from ANCOVAs for post-test scores in perceived proficiency in Italian, perceived immersion quantity and quality, and perceived opportunities

\begin{tabular}{|c|c|c|c|c|c|c|c|c|c|c|c|c|}
\hline & \multicolumn{3}{|c|}{ Proficiency Italian 2} & \multicolumn{3}{|c|}{ Immersion quantity ${ }^{2}$} & \multicolumn{3}{|c|}{ Immersion quality $^{2}$} & \multicolumn{3}{|c|}{ Opportunities $^{2}$} \\
\hline & $F$ & $p$ & $\eta^{2}$ & $F$ & $p$ & $\eta^{2}$ & $F$ & $p$ & $\eta^{2}$ & $F$ & $p$ & $\eta^{2}$ \\
\hline Model & 12.45 & $<.001$ & .44 & 1.89 & .14 & .08 & .29 & .84 & .01 & 2.81 & .04 & .12 \\
\hline Group & 3.16 & .04 & .09 & 2.69 & .08 & .08 & .43 & .65 & .01 & 4.15 & .02 & .11 \\
\hline Orient origin 1 & 1.64 & .21 & .03 & .92 & .34 & .01 & .00 & .99 & $<.001$ & .62 & .44 & .01 \\
\hline Proficiency Italian ${ }^{1}$ & 35.91 & $<.001$ & .36 & & & & & & & & & \\
\hline
\end{tabular}

${ }^{1}$ pre-test; ${ }^{2}$ post-test 
Italian was also associated to initial perceived proficiency in Italian $[F(2,68)=35.91, p<$ $\left..001, \eta^{2}=.36\right]$.

Post hoc analyses suggest that the RVL group outperformed the control group in post-test perceived proficiency in Italian [mean difference $=.69, p=.04,95 \% \mathrm{CI}=.01 ; 1.37$ ], and in perceived opportunities [mean difference $=.65, p=.02,95 \% \mathrm{CI}=.10 ; 1.21$ ]

According to the ANCOVAs, group was not significantly associated to post-test scores in orientation towards origin or host culture, or to applicable or conceptual knowledge of intercultural competence. Each post-test variable was significantly associated to the respective initial scores. Pre-test orientation towards origin culture was significantly associated to posttest applicable knowledge of intercultural competence (see Table 6).

\section{Discussion}

Promoting intercultural competence is an urgent policy in an increasingly interconnected society. To this end, several educational institutions are increasing their efforts in offering to their students opportunities to develop intercultural competence. Study abroad programmes represent one of the main examples of such efforts. However, the exposure to cultural differences entailed in study abroad programmes does not guarantee gains in intercultural competence unless students' reflection is explicitly supported (Engberg et al., 2016; LantzDeaton, 2017). The present study aims at contributing to this issue by testing the efficacy of a reflective activity on experienced cultural differences, embedded in a study abroad programme course.

The research hypothesis was partially confirmed. The RVL intervention improved students' perceived proficiency in Italian and perceived opportunities for cultural reflection, but it did not contribute to improve students' applicable and conceptual knowledge of intercultural competence. On a positive note, the RVL intervention successfully improved variables that are associated to intercultural competence. Descriptive results showed that our sample (representative of the population of undergraduate US study abroad students) had a limited proficiency in languages and prior experience of cultural differences. Both these variables are associated to intercultural competence development (Behrnd \& Porzelt, 2012; Bennett et al., 2003; Cubillos \& Ilvento, 2012; Cui, 2016; Jackson, 2011; Mamman, 1995; Shannon \& Begley, 2008). Overall, this pattern describes our sample as individuals with a low background

Table 6 Results from ANCOVAs for post-test scores in orientation towards origin and host culture, applicable, and conceptual knowledge of intercultural competence

\begin{tabular}{|c|c|c|c|c|c|c|c|c|c|c|c|c|}
\hline & \multicolumn{3}{|c|}{ Orient_origin ${ }^{2}$} & \multicolumn{3}{|c|}{ Orient_host ${ }^{2}$} & \multicolumn{3}{|c|}{$\begin{array}{l}\text { Applicable } \\
\text { knowledge }^{2}\end{array}$} & \multicolumn{3}{|c|}{$\begin{array}{l}\text { Conceptual } \\
\text { knowledge }^{2}\end{array}$} \\
\hline & $F$ & $p$ & $\eta^{2}$ & $F$ & $p$ & $\eta^{2}$ & $F$ & $p$ & $\eta^{2}$ & $F$ & $p$ & $\eta^{2}$ \\
\hline Model & 4.44 & .01 & .18 & 4.47 & .003 & .23 & 2.89 & .03 & .16 & 2.24 & .08 & .15 \\
\hline Group & .73 & .49 & .02 & .82 & .45 & .03 & .58 & .57 & .02 & .63 & .54 & .02 \\
\hline Orient_origin 1 & 12.89 & .001 & .18 & .20 & .66 & .003 & 3.98 & .05 & .06 & .03 & .88 & $<.001$ \\
\hline Orient_host $\mathrm{t}^{1}$ & & & & 12.75 & .001 & .18 & & & & & & \\
\hline Applicable knowledge1 & & & & & & & 8.74 & .004 & .13 & & & \\
\hline Conceptual knowledge $^{1}$ & & & & & & & & & & 8.36 & .01 & .14 \\
\hline
\end{tabular}

${ }^{1}$ pre-test; ${ }^{2}$ post-test 
preparation for significantly benefiting from a study abroad experience. The RVL was more effective than the control group in boosting students' background variables related to intercultural competence development.

On a negative side, neither the RVL nor the VL contribute to intercultural competence development. The intervention was partially inspired by Busse and Krause's problem-based intercultural learning unit (2016). In their study, authors tested the efficacy of two interventions, differing by the engagement with critical incidents: an affective-experiential one (critical incidents were acted out as role plays) and an analytical one (critical incidents were analysed in groups). Both intervention groups outperformed the control group in applicable and conceptual knowledge of intercultural competence. A few differences between our approach and Busse and Krause's approach may explain the differences in outcomes. Firstly, Busse and Krause's interventions were longer (six lessons) than our interventions (three lessons for the RVL or two lessons for the VL) and included several components: explanation of intercultural competence, analysis of film clips, simulation games, and analysis of critical incidents. Secondly, and most importantly, in the intervention, Busse and Krause's participants where explicitly provided with a definition of intercultural competence and taught how to assess critical incidents, with the same prompts as the ones used in the post-test assessment. This design may have induced a training effect. In our research design, the assessment of intercultural competence was included as a transfer measure.

An examination of correlational scores showed that all variables were associated across time. While this is expected for language proficiency or acculturation scores, the fact that also conceptual and applicable knowledge of intercultural competence correlated from the pre- to the post-test may not be a positive result. Pre-test assessment was given before any instruction on intercultural communication or intercultural competence was delivered; thus, students answered based on their preconceived notions. These naïve theories continue to influence students' applicable and conceptual knowledge of intercultural competence even after instruction (and intervention) was delivered. An analysis of the descriptive scores suggests that this may depend on the fact that instruction and interventions may have failed in inducing a conceptual change. On a positive note, all key variables significantly changed over time: language proficiency, orientation towards host culture, and applicable and conceptual knowledge of intercultural competence improved, whereas orientation towards origin culture decreased. It must be noticed that students were initially characterized by a relatively high orientation towards the origin culture, an aspect that has been suggested to be detrimental for intercultural competence development (Tarchi et al., 2019). This pattern supports the overall beneficial effects of study abroad experience.

\section{Limitations and directions for future research}

When interpreting the findings of the current study, some limitations should be taken into account. Firstly, the intervention was designed to be brief in order to be conceived as an activity to embed in study abroad courses without taking away too much space for other topics. The limited length of the intervention however may have limited the efficacy of the intervention. Future studies should extend the current design of the intervention by including a lecture targeting intercultural competence (rather than a specific component such as intercultural sensitivity) and provide more reflective opportunities to students (rather than reflecting through just one video-log). 
Secondly, in the present study only, transfer measures were included; thus, the efficacy of the intervention on proximal outcomes was not tested. In the reflective activity (RVL), students were asked to assign video-logs to an intercultural sensitivity stage. This activity could be re-designed as an assessment measure and included as a proximal measure of intervention efficacy.

Thirdly, the quality of the reflections may have depended on the quality of video-logs produced. Past research has shown that students are not necessarily able to create critical incidents based on their past experiences (Tarchi et al., 2019). Future research may include instructions on what critical incidents are and teach students how to transform their narration into a critical incident.

Finally, several other individual-level variables may have interfered with the results of the study. Unfortunately, the sample size was not large enough to investigate potentially moderating effects of age or gender. Future studies should focus on these variables, as well as include an in-depth examination of the participants family background (e.g., whether they are descendants of Italian migrants) or the actual quality of intercultural experiences during the study abroad experience.

\section{Conclusion}

Despite the limitations, the present study contributes to the literature on study abroad students' intercultural competence in several ways. Firstly, it designed a method to assess students' intercultural competence based on the narratives of their own experiences. Narrating is a sensemaking process, a way through which an individual expresses his/her orientation to a relevant situation (Daiute, 2014). As such, narratives are a promising way to elicit reflection on our own experiences. Secondly, the present study contributed to describe the initial background preparation of study abroad students, and what competences or perceptions they develop over the study abroad semester. Intercultural competence development is generally taken for granted and hardly ever assessed, and very rarely students' perceived proficiency in intercultural contexts is taken into consideration. Thirdly, the present study contributes to validate a methodology to increase study abroad students' perceived proficiency in the host language and their perceived opportunities for cultural experiences. These variables are associated with gains in intercultural competence and it is particularly important to discover ways to support them especially in the population of individuals who are experiencing a new cultural diversity context and intercultural communication for the first time (i.e., "beginning" sojourners). This is particularly important for those study abroad programmes in which students are included in classes consisting of only co-nationals, and that are taught in their mother tongue language. In these "island" programmes, opportunities to experience cultural differences are not many and it is important to maximize reflection upon these.

Supplementary Information The online version contains supplementary material available at https://doi.org/ 10.1007/s10212-021-00554-0.

Funding Open access funding provided by Università degli Studi di Firenze within the CRUI-CARE Agreement. 


\section{References}

Akkerman, S. F., \& Bakker, A. (2011). Boundary crossing and boundary objects. Review of Educational Research, 81(2), 132-169. https://doi.org/10.3102/0034654311404435.

Anderson, P. H., Lawton, L., Rexeisen, R. J., \& Hubbard, A. C. (2006). Short-term study abroad and intercultural sensitivity: A pilot study. International Journal of Intercultural Relations, 30(4), 457-469. https://doi.org/ 10.1016/j.ijintrel.2005.10.004.

Behrnd, V., \& Porzelt, S. (2012). Intercultural competence and training outcomes of students with experiences abroad. International Journal of Intercultural Relations, 36(2), 213-223. https://doi.org/10.1016/j.ijintrel. 2011.04.005.

Bennett, M. J. (1986). A developmental approach to training for intercultural sensitivity. International Journal of Intercultural Relations, 10(2), 179-196. https://doi.org/10.1016/0147-1767(86)90005-2.

Bennett, M. J. (1993). Towards ethnorelativism: A developmental model of intercultural sensitivity. In R. M. Paige (Ed.), Cross-cultural orientation: New conceptualizations and applications (pp. 27-70). New York, NY: University Press of America.

Bennett, J., Bennett, M., \& Allen, W. (2003). Developing intercultural competence in the language classroom. In D. Lange \& M. Paige (Eds.), Culture as the core: Perspectives on culture in second language learning (pp. 237-270). Greenwich, CT: Information Age Publishing.

Berry, J. W. (1974). Psychological aspects of cultural pluralism: Unity and identity reconsidered. In R. Brislin (Ed.), Topics in culture learning (pp. 17-22). Honolulu, HA: East-West Culture Learning Institute.

Berry, J. W. (1997). Immigration, acculturation, and adaptation. Applied Psychology, 46(1), 5-34. https://doi.org/ 10.1111/j.1464-0597.1997.tb01087.x.

Berry, J. W. (2005). Acculturation: Living successfully in two cultures. International Journal of Intercultural Relations, 29(6), 697-712. https://doi.org/10.1016/j.ijintrel.2005.07.013.

Bird, A., Medenhall, M., Stevens, M., \& Oddou, G. (2010). Defining the content domain of intercultural competence for global leaders. Journal of Managerial Psychology, 25(8), 810-828. https://doi.org/10. $1108 / 02683941011089107$.

Busse, V., \& Krause, U.-M. (2015). Addressing cultural diversity: effects of a problem-based intercultural learning unit. Learning Environments Research, 18(3), 425-452. https://doi.org/10.1007/s10984-015-9193-2.

Busse, V., \& Krause, U.-M. (2016). Instructional methods and languages in class: A comparison of two teaching approaches and two teaching languages in the field of intercultural learning. Learning and Instruction, 42, 83-94. https://doi.org/10.1016/j.learninstruc.2016.01.006.

Chen, G.-M., \& Starosta, W. J. (1996). Intercultural communication competence: A synthesis. Annals of the International Communication Association, 19(1), 353-383. https://doi.org/10.1080/23808985.1996. 11678935

Chen, G.-M., \& Starosta, W. J. (1997). A review of the concept of intercultural sensitivity. Human Communication, 1, 1-16 https://files.eric.ed.gov/fulltext/ED408634.pdf. Accessed 28 March 2021.

Cubillos, J. H., \& Ilvento, T. (2012). The impact of study abroad on students' self-efficacy perceptions. Foreign Language Annals, 45(4), 494-511. https://doi.org/10.1111/j.1944-9720.2013.12002.x.

Cui, Q. (2016). A study of factors influencing students' intercultural competence. Journal of Language Teaching and Research, 7(3), 433. https://doi.org/10.17507/j1tr.0703.01.

Daiute, C. (2014). Narrative inquiry: A dynamic approach. Thousand Oaks, CA: SAGE Publications.

Deardorff, D. K. (2006). Identification and assessment of intercultural competence as a student outcome of internationalization. Journal of Studies in International Education, 10(3), 241-266. https://doi.org/10.1177/ 1028315306287002 .

Deardorff, D. K. (2009). The SAGE handbook of intercultural competence. Thousand Oaks, CA: SAGE Publications.

Deardorff, D. K. (2011). Assessing intercultural competence. New Directions for Institutional Research, 149, 6579.

Deardorff, D. K. (2015). Intercultural competence: Mapping the future research agenda. International Journal of Intercultural Relations, 48, 3-5. https://doi.org/10.1016/j.ijintrel.2015.03.002.

Engberg, M. E., Jourian, T. J., \& Davidson, L. M. (2016). The mediating role of intercultural wonderment: Connecting programmatic components to global outcomes in study abroad. Higher Education, 71(1), 21-37. https://doi.org/10.1007/s10734-015-9886-6.

Fitzgerald, M. H. (2001). Gaining knowledge of culture during professional education. In J. Higgs \& A. Titchen (Eds.), Practice knowledge and expertise in the health professions (pp. 149-156). Melbourne, VIC: Butterworth Heinemann.

Flanagan, J. C. (1954). The critical incident technique. Psychological Bulletin, 51(4), 327-358. https://doi.org/10. $1037 / \mathrm{h} 0061470$ 
Hammer, M. R. (2011). Additional cross-cultural validity testing of the Intercultural Development Inventory. International Journal of Intercultural Relations, 35(4), 474-487. https://doi.org/10.1016/j.ijintrel.2011.02. 014.

Hammer, M. R. (2015). The Developmental paradigm for intercultural competence research. International Journal of Intercultural Relations, 48, 12-13. https://doi.org/10.1016/j.ijintrel.2015.03.004.

Hammer, M. R., Bennett, M. J., \& Wiseman, R. (2003). Measuring intercultural sensitivity: The intercultural development inventory. International Journal of Intercultural Relations, 27(4), 421-443. https://doi.org/10. 1016/S0147-1767(03)00032-4.

Holt, K., \& Seki, K. (2012). Global leadership: A developmental shift for everyone. Industrial and Organizational Psychology, 5(2), 196-215. https://doi.org/10.1111/j.1754-9434.2012.01431.x.

Jackson, J. (2011). Host language proficiency, intercultural sensitivity, and study abroad. Frontiers: The Interdisciplinary Journal of Study Abroad, 21(1), 167-189.

Javidan, M., \& Teagarden, M. B. (2011). Conceptualizing and measuring global mindset. Advances in Global Leadership, 6, 13-39. https://doi.org/10.1108/S1535-1203(2011)0000006005.

Kolb, D. A. (1984). Experiential learning: Experience as the source of learning and development. Englewood Cliffs, NJ: Prentice Hall.

Kolb, D. A., Boyatzis, R. E., \& Mainemelis, C. (2001). Experiential learning theory: Previous research and new directions. In R. J. Sternberg \& L. F. Zhang (Eds.), Perspectives on thinking, learning, and cognitive styles (pp. 227-248). London, UK: Lawrence Erlbaum.

Lantz-Deaton, C. (2017). Internationalisation and the development of students' intercultural competence. Teaching in Higher Education, 22(5), 532-550. https://doi.org/10.1080/13562517.2016.1273209.

Larzén-Östermark, E. (2011). Intercultural sojourns as educational experiences: A narrative study of the outcomes of Finnish student teachers' language-practice periods in Britain. Scandinavian Journal of Educational Research, 55(5), 455-473. https://doi.org/10.1080/00313831.2010.537687.

Leung, K., Ang, S., \& Tan, M. L. (2014). Intercultural competence. Annual Review of Organizational Psychology and Organizational Behavior, 1(1), 489-519. https://doi.org/10.1146/annurev-orgpsych031413-091229.

Mamman, A. (1995). Expatriates' intercultural effectiveness: Relevant variables and implications. Asia Pacific Journal of Human Resources, 33(1), 40-59. https://doi.org/10.1177/103841119503300103.

Olson, C. L., \& Kroeger, K. R. (2001). Global competency and intercultural sensitivity. Journal of Studies in International Education, 5, 116-137. https://oi.org/10.1177/102831530152003.

Paige, M., \& Vande Berg, M. (2012). Why students are and are not learning abroad. A review of recent research. In M. Vande Berg, M. Paige, \& K. H. Lou (Eds.), Student learning abroad: What our students are learning, what they're not, and what we can do about it (pp. 29-60). Sterling, VA: Stylus Publishing.

Sandberg, J. (2000). Understanding human competence at work: An interpretative approach. Academy of Management Journal, 43(1), 9-25. https://doi.org/10.5465/1556383.

Shannon, L. M., \& Begley, T. M. (2008). Antecedents of the four-factor model of cultural intelligence. In S. Ang \& L. Van Dyne (Eds.), Handbook of cultural intelligence theory, measurement, and applications (pp. 4155). Thousand Oaks, CA: Sage.

Spitzberg, B., \& Changnon, G. (2009). Conceptualizing intercultural competence. In The SAGE Handbook of Intercultural Competence (pp. 2-52). Thousand Oaks, CA: Sage.

Tarchi, C., Surian, A., \& Daiute, C. (2019). Assessing study abroad students' intercultural sensitivity with narratives. European Journal of Psychology of Education, 34(4), 873-894. https://doi.org/10.1007/s10212019-00417-9.

Vande Berg, M., Paige, M., \& Hemming Lou, K. (2012). Student learning abroad: What our students are learning, what they're not, and what we can do about it. Sterling, Va: Stylus.

Ward, C., \& Rana-Deuba, A. (1999). Acculturation and adaptation revisited. Journal of Cross-Cultural Psychology, 30(4), 422-442. https://doi.org/10.1177/0022022199030004003.

Wight, A. R. (1995). The critical incident as a training tool. In S. M. Fowler \& M. G. Mumford (Eds.), Intercultural sourcebook: Cross-cultural training methods (pp. 127-140). Boston, MA: Intercultural Press.

Wong, B., \& Butler, D. L. (2012). Learning about learning disabilities (fourth ed.). Waltham, MA: Academic Press Inc..

Wong, E. D., \& Webster, A. (2012). Using digital video logs to promote global competency in study abroad programs [Paper Presentation]. Denver, CO: The Forum on Education Abroad.

World Medical Association. (2013). Declaration of Helsinki: Ethical principles for medical research involving human subjects. JAMA, 310(20), 2191-2194. https://doi.org/10.1001/jama.2013.281053.

Publisher's note Springer Nature remains neutral with regard to jurisdictional claims in published maps and institutional affiliations. 
Christian Tarchi. Dept. of Education, Languages, Intercultures, Literatures and Psychology (University of Florence), via San Salvi, 12 - 50125 Florence, Italy. Email: christian.tarchi@unifi.it

Current Themes of Research:

Critical thinking and multimedia learning. The role of motivational and cognitive factors in comprehending and recalling from text. Emergent literacy. Study abroad programmes and the development of cross-cultural awareness.

Most relevant publications in the field of Psychology of Education:

Tarchi, C., Zaccoletti, S., \& Mason, L. (2020). Learning from text, video, or subtitles: A comparative analysis. Computers \& Education, 104034. doi: 10.1016/j.compedu.2020.104034

Tarchi, C. \& Mason, L. (2020). Effects of critical thinking on multiple-document comprehension. European Journal of Psychology of Education, 35, 289-313. doi: 10.1007/s10212-019-00426-8

Tarchi, C., Bigozzi, L. \& Pinto, G. (2019). The influence of narrative competence on mental state talk in kindergarten and primary school children. British Journal of Developmental Psychology, 37, 535-550. doi: 10.1111/BJDP.12295

Tarchi, C., Surian, A. \& Daiute, C. (2019). Assessing study abroad students' intercultural sensitivity with narratives. European Journal of Psychology of Education, 34, 873-894. doi: 10.1007/s10212-019-00417-9

Tarchi, C. (2017). Comprehending expository texts: The role of cognitive and motivational factors. Reading Psychology, 38, 154-181. DOI: 10.1080/02702711.2016.1245229.

Alessio Surian. University of Padua. Padua, Italy

Current Themes of Research:

Narratives and critical incidents in professional education, with specific reference to situational judgement testing. Social interaction and cultural diversity sensibility in Medical and Cross-cultural education.

Most relevant publications in the field of Psychology of Education:

Surian A., Di Masi D. (2017) Supporting Higher Education-Hospital transition through blended learning. Frontiers in Education, doi:10.3389/feduc.2017.00060

Surian A., Serbati A. (2017). Recognition of learning in informal and nonformal contexts: Examples and reflections from the DARE+ experience, in Yerosh M., Serbati A. Seery A. (eds.) "Developing Generic Competences Outside the University Classroom", Granada, Editorial Universidad de Granada

Surian A., Greco C., Mahmud M., Mantovani G. (2017) Learning history as views sharing: Examples of collaborative practices, in Portera A., Grant C. A. Intercultural education and competences. Challenges and Answers fro the Global World, Cambridge Scholars Publishing, pp. 159-172

Surian A. (2016) Adolescent Learners, in Danver S.L. (ed.) The SAGE encyclopedia of online education. SAGE, New York

Surian A. (ed.) (2016). Open spaces for interactions and learning diversities. Rotterdam NL, Sense 